Centro de Estudios Constitucionales de Chile Universidad de Talca

"A propósito del carácter fundamental de los derechos económicos, sociales y culturales. Una mirada desde la doctrina comparada y la experiencia del ordenamiento jurídico cubano"

Karel Pachot

\title{
A PROPÓSITO DEL CARÁCTER FUNDAMENTAL DE LOS DERECHOS ECONÓMICOS, SOCIALES Y CULTURALES. UNA MIRADA DESDE LA DOCTRINA COMPARADA Y LA EXPERIENCIA DEL ORDENAMIENTO JURÍDICO CUBANO
}

\author{
ON FUNDAMENTALITY OF THE ECONOMIC, SOCIAL AND CULTURAL RIGHTS.
}

\author{
A LOOK FROM THE COMPARATIVE DOCTRINE AND THE \\ Cuban LaW EXPERIENCE
}

\begin{abstract}
Karel Pachot ${ }^{2}$
Vicedecano Docente Facultad de Derecho, Universidad de Oriente, Santiago de Cuba

kpachot@fd.uo.edu.cu
\end{abstract}

RESUMEN: En la actualidad uno de los temas más recurrentes entre los estudiosos del Derecho Constitucional orbita en torno al reconocimiento del carácter fundamental de determinados derechos, los cuales se ponderan como indispensables y disponibles para la concreción de la dignidad humana. En este contexto han quedado minimizados en algunos ordenamientos jurídicos como tales los derechos económicos, sociales y culturales, toda vez que queda planteado su diferida aplicabilidad y su eficacia no directa, asi como su relativa justiciabilidad.

Precisamente este estudio ofrece un conjunto de argumentos que permiten predicar y ordenar juridicamente el necesario y posible reconocimiento del valor fundamental de estos derechos, toda vez que deben concebirse como concluyentes para la afirmación plena y fáctica de la dignidad humana.

ABSTRACT : Nowadays, one of the most recurrent issues among the specialists of Constitutional Law consists of the fundamental character of some rights which are considered as indispensable or essential and available for the concretion of human dignity. In this context there are some rights which are minimized in some legislation, these are economic, social and cultural rights which reserved applicability, indirect effectiveness, as well as its relative actionability are established. This work offers some arguments that allow to preach and order, from the juridic view point, the necessary and possible recognition of

\footnotetext{
${ }^{1}$ Artículo enviado el 20 de noviembre de 2009 y aprobado el 22 de enero de 2010 Licenciado en Derecho (2001).

${ }^{2}$ Doctor en Ciencias Jurídicas (2007). Profesor de Derecho Constitucional, Vicedecano Docente y Secretario del Consejo Científico de la Facultad de Derecho de la Universidad de Oriente, Santiago de Cuba. Miembro de la Sociedad Cubana de Derecho Constitucional y Administrativo, de la Unión Nacional de Juristas de Cuba, de la Cátedra de Estudios Históricos del Estado y del Derecho "Dr. Leonardo Griñán Peralta" de la Universidad de Oriente, del Instituto Brasileño de Derecho Deportivo y del Instituto Iberoamericano de Derecho Deportivo.
} 
the fundamental value of those rights, since they should be conceived as conclusive to the real and full affirmation of human dignity.

PALABRAS CLAVE: Constitución, derechos humanos, derechos fundamentales, justiciabilidad de los derechos fundamentales, derechos económicos, sociales y culturales.

KEY WORDS: Constitution, Human Rights, Fundamentals Rights, direct applicability of rights, Economic, Social and Cultural Rights.

\section{Planteamiento inicial Del tema}

La problemática de la determinación inequívoca de un concepto relativo a los derechos fundamentales o absolutos ocupa, sin lugar a dudas, una de las cuestiones que actualmente mayor atención provoca en una considerable parte de la comunidad académica dedicada a los estudios jurídico-constitucionales. De tal modo, desde nuestro punto de vista, los constitucionalistas reiteradamente hemos pretendido -no en pocas ocasiones insatisfactoriamente- darle una determinación al concepto de derechos fundamentales siempre desde una (reducida) visión estrictamente técnico-jurídica. Esta conceptualización, inobjetablemente, puede considerarse una valedera, y no menos importante, intención en la búsqueda definitiva de los contornos técnico-jurídicos -deseables de precisión- sin los cuales no pudiera reivindicarse absolutamente el ejercicio y goce plenos por parte de los titulares de estos derechos, aun cuando no debe obviarse que, en ocasiones, puede sugerirse extremadamente tecnicista y poco trascendente para el concepto en sí, que, en definitiva, exige una apreciación multidimensional, que no sólo arroje respuestas desde la positivación de estos derechos o del reconocimiento a los mismos de un conjunto de garantías jurisdiccionales de protección. Por demás, un concepto que rebasa toda certidumbre basada exclusivamente en el Derecho, por cuanto se trata de uno de los pilares básicos sobre los que se erige toda sociedad contemporánea: los derechos fundamentales.

Tal es así que el debate suscitado en el ámbito académico-jurídico en torno a esta problemática se exhibe cual interminable laberinto cuando entonces la cuestión es pretender el reconocimiento del carácter fundamental de los derechos económicos, sociales y culturales (en lo adelante DESC). De tal modo, esta pretensión encuentra escollos difícilmente sorteables, y que desde la órbita de la doctrina científica constitucional lastra, disminuye o reduce -conduciendo a estériles discusiones, por momentos- el valor jurídico de los DESC, desconociendo que los mismos deben concebirse no sólo necesarios sino imprescindibles para la consecución plena e integral de la dignidad humana. Además, queda obviado el hecho de que no debemos menoscabar en su concepción indivisible los derechos fundamentales, toda vez que sólo bajo este presupuesto puede entenderse y predicarse juiciosamente la valía de los mismos. 
Por supuesto, este debate está indisolublemente ligado a la determinación de la necesaria e inmediata justiciabilidad de los DESC por las vías ordinarias o específicas de protección jurisdiccional que abarcan todo el universo de los derechos fundamentales, cuestión que, unida a la imprecisión de la dogmática particular de cada uno de estos derechos -que implicaría la determinación del contenido esencial de los mismos, o al menos de uno mínimo exigible de protección-, conduce al desmayo en las intenciones por reconocerle tal carácter a estos derechos por parte de constitucionalistas sostenedores de disímiles modelos de interpretación de los derechos fundamentales.

Por otra parte, desde el punto de vista del imprescindible análisis técnicojurídico de la regulación constitucional de los DESC, diferentes cuestiones suscitan un interés particular y son de ineludible acercamiento, toda vez que aún está pendiente en la doctrina un desarrollo teórico en torno a los mismos, tratándose hasta el momento de derechos glosados más retóricamente que construidos técnicojurídicamente. Debe recordarse oportunamente que esta pretendida construcción teórica de los DESC no culmina en el reconocimiento formal que de los mismos se derive en las Constituciones, sino, por el contrario, parte inicialmente de éste extendiendo sus horizontes hasta lo que bien pudiera denominarse el limes jurídico de todos los ámbitos sociales.

Tal panorama exhibido en la doctrina jurídica, aún pendiente de resolución definitiva, incluso, a partir de la positivación que han recibido los derechos fundamentales en los ordenamientos jurídicos, focaliza mucha mayor trascendencia en las sociedades latinoamericanas, inmersas en una agónica e histórica deuda económica y social con considerables sectores o grupos sociales, para nada irrelevantes, y que, precisamente con respecto al ejercicio y goce plenos de los DESC, han sufrido elevados costos de disminución en su realización efectiva. Ante esta situación, la motivación que incentivó las siguientes líneas, para nada considerables más allá que unas breves reflexiones, fue ofrecer un conjunto de argumentos, esbozados en el orden teórico y doctrinal, con el propósito de exponer una mejor ponderación de los DESC, a partir de una concepción no excluyente ni reduccionista de derechos fundamentales. Con ello, se pretende, además, coadyuvar a una mejor comprensión y entendimiento que de los mismos se tenga no sólo por parte de los investigadores del Derecho sino además por cualquier persona o individuo, titular de los mismos en toda sociedad.

\section{Tras los CAUCES HistÓRICO-CONSTITUCIONALES \\ DE LOS DERECHOS FUNDAMENTALES}

Ciertamente el término "derechos fundamentales" es relativamente de reciente aparición en el constitucionalismo moderno. Si bien es cierto, siguiendo a PérEZ 
LUÑO, ${ }^{3}$ que la expresión droits fundamentaux aparece en Francia hacia la década de 1770 en el marco del movimiento político, ideológico y cultural que condujo a la Declaración de Derechos del Hombre y del Ciudadano de 1789, su formulación jurídico-positiva en los textos constitucionales no fue expresa hasta que el constitucionalismo alemán (identificándolo como Grundrechte) lo acuñara inicialmente en la Constitución de Frankfurt en 1848, rescatándolo luego en la Constitución de Weimar (1919) y definitivamente en la Ley Fundamental de Bonn (1949). Para el constitucionalismo latinoamericano su incorporación es un legado de la impronta del constitucionalismo cubano, toda vez que fue la Constitución cubana de 1940 la pionera en su empleo.

Sin embargo, no sería prudente ignorar que la reivindicación de determinados derechos, considerados en cada momento histórico como derechos "fundamentales", plasmados incluso en determinados documentos, antecede por muchos años, incluso siglos, el reconocimiento de aquellos comprendidos definitivamente en el concepto actual de derechos fundamentales. Así, por ejemplo, pueden hallarse los primeros derechos demandados, y considerados siempre como inherentes a la persona humana, en los Fueros españoles de León (1020), Jaca (1064), Najera (1075), Toledo (1085), Zaragoza (1115) y Aragón (1283), los Privilegios de la Unión Aragonesa (1287) y la Bula de Oro húngara (1222). Por su parte, en Inglaterra fueron inscritos posteriormente determinados derechos en la Carta Magna de Libertades otorgada por el rey Juan Sin Tierra (1215), la Petición de Derechos (1628), la Ley del Habeas Corpus (1679), y la Declaración de Derechos (1689). Este último documento puede considerarse como el primero de carácter general que contiene los enunciados de los derechos y libertades civiles y políticas, así como ciertas garantías procesales para los mismos.

Posteriormente, el liberalismo burgués, influenciado por el Iusnaturalismo y el Racionalismo Ilustrado, plasmó en declaraciones jurídicamente no vinculantes los derechos conocidos como individuales, ya fueran civiles o políticos, erigidos frente al poder ilimitado de intromisión de la autoridad pública en la esfera privada del individuo que se proclamaba desde el absolutismo monárquico de mediados y finales del siglo XVIII, impugnando los soportes legitimadores del Ancien Régime. En esta etapa se enmarcaron las Revoluciones Americana y Francesa, las que aportaron importantes documentos contentivos de derechos, como lo fueron, en el primer caso, las Declaraciones de Derechos del Pueblo de Virginia (1776), de Independencia (1776) y de Derechos (esta última conocida como el Bill of Rights) incorporada en 1791 a la Constitución Federal. Mientras, en Francia se promulgaron las Declaraciones de los Derechos del Hombre y del Ciudadano de

${ }^{3}$ Cfr. Pérez Luño (1994) pp. 29 y ss. 
1789 y 1793, las que influyeron notablemente en la elaboración y aprobación de la actual Declaración Universal de los Derechos Humanos de 1947.

De hecho, la demora con que el constitucionalismo americano asistió al reconocimiento formal de una serie de derechos esenciales para la existencia humana no fue obra de un olvido de los llamados Padres Fundadores de la Unión Americana. La inclusión posterior del Bill of Rights, motivada a raíz del proceso de ratificación estadual del proyecto de Constitución Federal, se debió inicialmente al debate suscitado entre antifederalistas y federalistas, en torno al problema que significaría el enfrentamiento de los principios de legalidad (encarnador de la soberanía parlamentaria) y el principio de constitucionalidad (viabilizador del principio de soberanía popular). De este modo se concebían antagónicas estas posiciones, una, la primera, reclamando el establecimiento de una carta de derechos, mientras, la segunda, negaría la necesidad de hacerlo por considerar que el pueblo conserva todos sus derechos y poderes más allá de una prescripción legal. ${ }^{4}$

Durante este período inicial (pudiendo entenderse el mismo a partir de todo el siglo XIX y hasta los inicios del XX) la mayor parte de los textos constitucionales respondieron a una marcada ideología liberal. De ahí que los derechos proclamados en los mismos no pudieran ser considerados los derechos de todos los hombres, sino los del hombre burgués (para quien, por ejemplo, el derecho de propiedad privada se concibe con carácter absoluto e inviolable) siendo considerados patrimonio del individuo en su condición presocial. ${ }^{5}$ Esta concepción de los derechos fundamentales, donde exclusivamente se entendieron los mismos como los derechos de libertad del individuo frente al Estado, destacaron el status negativus de la libertad, no permitiendo restricción alguna a la misma e, incluso, marcaron un vínculo negativo del legislador hacia los mismos, desconociendo los presupuestos sociales y valorativos que dimensionan los derechos fundamentales. A este primer grupo se les denominó como primera generación histórica de derechos, incluyéndose entre ellos los derechos civiles y políticos.

Mediante los mismos, consecuentemente, se enarboló un ámbito de privacidad donde el individuo no podía ser molestado, pero tras el cual se vincularon los intereses económicos de la burguesía y se forjó un modelo de hombre de espaldas a la sociedad. Por otra parte, estos derechos enmarcaron un espacio vital para el desenvolvimiento de las personas en la vida sociopolítica, siendo considerados derechos de corte individual y de ámbito personal, invocadores de la libertad humana, expresión de la autonomía personal en las sociedades. Incluso, se puede identificar la existencia de dos ámbitos de ejercicio de estos derechos, uno tipificado por las

${ }^{4} \mathrm{Al}$ respecto, vid. Pérez Royo (1997) pp. 247 y ss.

${ }^{5}$ Cifr. Ídem, p. 38. 
actuaciones personalísimas (caracterizada por la dignidad de la persona, entre los que destacan los derechos a la vida, a la integridad corporal, la libertad de creencia religiosa, a la vida privada, inviolabilidad del domicilio, secreto de correspondencia, libertad de circulación, libertad de residencia, derecho de propiedad), y otro conformado por comportamientos de ámbito público y determinado por la relación del individuo con sus semejantes (libertad de expresión, libertad de información, derecho de reunión, manifestación, asociación, petición, participación en la vida política, sufragio).

Posteriormente, la inclusión de la temática social en el debate en torno a la concepción de los derechos fundamentales, tal y como advierte Villabella ARMENGOL, ${ }^{6}$ aunado a la inminente crisis generada en el Estado Liberal, provocaron la aparición de la segunda generación histórica de derechos (gestándose la misma desde mediados del siglo XIX y consolidándose a partir del período de entreguerras mundiales), cuyo catálogo de derechos se identifica esencialmente con los DESC. Obviamente, los mismos tuvieron su punto de partida en aquella antecesora teoría individualista de los derechos fundamentales, determinando la consecución de un mayor grado de justicia e igualdad social, ante la patente realidad de que aquel primer cuerpo de derechos se tornó insuficiente en la concreción del desarrollo pleno de la dignidad humana.

Sin embargo, su incorporación inicial a textos declarativos o normativos data, incluso, de la última década del siglo XVIII, observándose los primeros referentes en los artículos 17, 21 y 22 de la Declaración de Derechos del Hombre y del Ciudadano (1793) incorporada como preámbulo a la Constitución de ese año (recuérdese que la misma nunca llegó a entrar en vigor). A la postre, su aparición en la Constitución francesa de 1848 (véase los artículos 10 y 13) significó cómo la misma pretendió erigirse como la declaración de la igualdad, tal como su predecesora de 1789 lo había sido de la libertad.

Más allá de ello, no es hasta las dos primeras décadas del pasado siglo en el que comienza a formularse vertiginosamente su pleno reconocimiento constitucional, ante todo como consecuencia de las repercusiones internacionales de la Revolución socialista en Rusia y de la crisis experimentada por el capitalismo liberal. En este sentido no debe omitirse el impacto provocado por la Declaración soviética de Derechos del Pueblo Trabajador y Explotado (1918) con respecto al posterior reconocimiento y desarrollo de los DESC no sólo en los textos constitucionales sino en los ordenamientos jurídicos nacionales. De hecho, ya su reivindicación frente a los clásicos derechos individuales se debió en gran medida al protagonismo histórico alcanzado anteriormente por el proletariado desde mediados del siglo

${ }^{6}$ Villabella Armengol (2000 a) pp. 312 y 313. 
XIX, desarrollando consecuentemente una conciencia de clase, circunstancia que de igual modo determinó su definitiva positivación en algunas constituciones de entonces.

Entre estas últimas cabe destacar las Constituciones mexicana, conocida también como Constitución de Querétaro (1917), primer intento de conciliar los derechos de libertad con los DESC, superando así los polos opuestos del individualismo y del colectivismo; la alemana de Weimar (1919), la republicana de España (1931), las rusas (1918 y 1936), y la irlandesa (1937).

En sí, estos derechos parten de invocar su titularidad no al hombre individual y abstracto, sino al hombre históricamente situado en una relación socioeconómica determinada, por lo que su intención es concretar la igualdad de éstos en la trama de relaciones sociales y económicas y, en consecuencia, exigir por su naturaleza una actitud asistencial y prestataria del Estado para su viabilidad. ${ }^{7}$ Entre los mismos se identifican: el derecho al trabajo, así como el resto de los derechos conexos a éste, como los derechos al descanso anual y semanal, a la jornada laboral de ocho horas, a una remuneración justa, a la seguridad y asistencia social; y, por otra, parte los derechos a la protección de la salud, a la educación, a la cultura y, recientemente, al deporte, entre otros.

Entre sus rasgos más relevantes pueden identificarse:

1. el desempeño de una función de ampliación, complemento y superación de los derechos proclamados en la etapa liberal clásica;

2. la preocupación por la satisfacción de las necesidades de carácter económico, asistencial, educativo y cultural, y

3. la implicación de la intervención activa de la organización pública en la cobertura de las necesidades o aspiraciones que intentan satisfacer; la eficacia redistribuidora de los beneficios del progreso social en orden a conseguir la realización efectiva de la igualdad jurídica, económica y social de todos los miembros de la sociedad y la especial atención a los miembros de aquellos sectores sociales considerados como particularmente débiles y vulnerables socialmente (enfermos, niños, mujeres, ancianos, trabajadores asalariados, refugiados, minorías, etc.). ${ }^{8}$

En definitiva, la constitucionalización de los derechos fundamentales ha venido respondiendo, en gran medida, a la reafirmación del valor jurídico de los textos constitucionales, identificados como la fuente superior de sus respectivos ordenamientos jurídicos, permitiendo, consecuentemente, un reforzamiento en el reconocimiento, ejercicio y protección de aquéllos. De hecho, el valor jurídico de la Constitución es uno de los rasgos que en la actualidad caracterizan el De-

\footnotetext{
${ }^{7}$ Ídem.

${ }^{8}$ Vid. un análisis detallado de sus principales caracteres en De CASTRO Cid (1993) pp. 34 y ss.
} 
recho Constitucional contemporáneo, rasgo que, incluso, ha sido positivado en los ordenamientos jurídicos. ${ }^{9}$

De este modo, la Constitución se torna en auténtico Derecho, debiendo considerarse como una norma directa e inmediatamente aplicable, e invocable ante los órganos judiciales y/o por todos los operadores jurídicos en su actuar cotidiano, gozando de fuerza vinculante para los órganos y funcionarios públicos, así como para todos los ciudadanos, en sentido general. Este carácter normativo-jurídico de la Constitución conducirá, de igual modo, a que ésta no deberá ser apreciada como una norma programática y declarativa, sino todo lo contrario: sus preceptos deberán ser directamente aplicables sin distinguir entre su inmediata o diferida efectividad.

Es así que se nos presentará la misma como la norma jurídica fundamental de una sociedad, con capacidad para dotar de justificación y legitimación política y jurídica, material y formal, al resto del universo normativo que integra el Derecho. Consecuentemente, la producción jurídica en la sociedad se derivará de ella. Es por ello que la Constitución se deberá entender como una norma jurídica cualitativamente distinta a las demás, una norma normarum, fundamental y fundamentadora, ubicándose en la cima del ordenamiento jurídico, del cual, definitivamente, forma parte.

Ante estos presupuestos, y en la medida que han evolucionado las concepciones ideológicas, políticas y filosóficas en las que se han sostenido los diferentes modelos de Estado, han sido positivados en los respectivos textos constitucionales los derechos fundamentales, más allá de su postulación en documentos declarativos que, por consiguiente, no imponen valor vinculante. Esos derechos, considerándose como tal un conjunto de valores éticos, filosóficos, religiosos, culturales, sociales y jurídicos (no reduciendo su concepto al de meras facultades, potestades, prerrogativas o instituciones), han sido objeto de atención de la humanidad desde antaño, acompañando las reivindicaciones del hombre por concretar las exigencias que en torno a la dignidad humana han respondido a cada momento histórico concreto. Al unísono, el influjo que en torno a los mismos han ejercido la libertad, la igualdad y la justicia social, cual principios fundamentales para la consecución del pleno desenvolvimiento de la personalidad humana, los han convertido en referentes sin paralelo alguno en los ejes centrífugos en torno a los cuales han girado las fundamentales exigencias de la humanidad..$^{10}$

\footnotetext{
${ }^{9}$ Con respecto al valor jurídico de la Constitución en la doctrina académica vid.: Pérez RoYo (1997) pp. 85 y ss.; Asensi Sabater (1996) pp. 77 y ss.; García de Enterría y Fernández (2004) p. 171; García Cotarelo y de Blas Herrero (1986) pp. 184 y ss.; Hakansson Nieto (2001) pp. 109 y ss.; Gelli (2001) pp. 255 y 256; Prieto Valdés (2000) pp. 26 y ss., Prieto Valdés (s.f.) pp. 143 y 144, y Prieto Valdés (2002) pp. 111 y ss.

${ }^{10}$ Pérez Luño (1994) p. 46.
} 
Por ello, todos los derechos fundamentales reconocidos constitucionalmente deberán gozar de los mecanismos de protección instaurados en el texto constitucional, unos más intensos y efectivos que otros, pero teniendo cada derecho las garantías que se derivan de su inserción concreta en la Constitución y de la función que la Constitución les atribuya. ${ }^{11}$ De este modo, las constituciones deben exponerse como fuente directa de derechos, algunos de los cuales estarán fundamentados directamente en la norma constitucional y no precisarán de legislación de desarrollo para ser efectivos. Más allá, en los supuestos en que la normativa complementaria sea necesaria para una completa eficacia del precepto constitucional, la determinación en éste de algunos contenidos esenciales de estos derechos permitirá el ejercicio inmediato de los mismos.

A su vez, la justiciabilidad inmediata, y con ello la defensa jurídica de estos derechos, se postulará inexcusable, toda vez que permitirá que sus titulares puedan acceder a las vías o mecanismos instituidos cuando aprecien una presunta violación, disminución, lesión o amenaza en el ejercicio y goce legítimos de éstos.

Esta incontestable realidad histórica no pudo ser obviada por las fuerzas sociales que han dominado o protagonizado los distintos escenarios políticos, incorporando en sus respectivos textos constitucionales los llamados catálogos de derechos fundamentales, más o menos extensos, que incluían aquellos derechos considerados esenciales para la existencia humana. De este modo, los derechos fundamentales se convirtieron paulatinamente en el núcleo esencial de la dogmática constitucional, evolucionando su concepción indisolublemente ligada al constitucionalismo moderno a partir de los inicios del siglo XIX, por lo que su reconocimiento jurídico al más elevado nivel jerárquico normativo se entenderá como un paso importante, llegando a ser incluso en algunos casos hasta imprescindible para su pleno ejercicio, dimensionándolos ya no sólo como significativas aspiraciones del ser humano, afirmativa de sus ideales, demandas, e incluso sus exigencias éticas en la vida social, sino además defendiéndolos como valores ineludibles en el devenir de la humanidad.

\section{EL CARÁCTER FUNDAMENTAL DE LOS}

DERECHOS ECONÓMICOS, SOCIALES Y CULTURALES

En la actualidad, el término "derechos fundamentales" ha sido empleado con mayor insistencia una vez positivados los derechos del hombre en los ordenamientos jurídicos, principalmente a partir de su constitucionalización, si bien también se puede llegar a aceptar que determinados derechos fundamentales llegan a ser

${ }^{11}$ Cfr. Freixes Sanjuán (1992) pp. 9 y ss. 
configurados legalmente. De tal modo, con este término se ha pretendido darles un sentido más preciso y estricto a los derechos inherentes de la persona humana, frente a unos contornos amplios e imprecisos que ofrece el término "derechos humanos", también empleado con frecuencia, pero que ha quedado reservado como una categoría del Derecho Internacional, ${ }^{12}$ mucho más, después que fuese mundializado en la Declaración Universal de 1947.

Consecuentemente, con el término "derechos fundamentales" se persigue delimitarlos espacial y temporalmente, respondiendo a su carácter fundamentador del sistema jurídico, político y económico de una sociedad, en lo que Pérez LuÑo considera como "aquellos derechos humanos garantizados por el ordenamiento jurídico positivo, en la mayor parte de los casos en su normativa constitucional, y que suelen gozar de una tutela reforzada". ${ }^{13}$

Comparto este punto de vista, toda vez que no pueden existir derechos fundamentales donde no se hayan reconocidos como tales en los ordenamientos jurídicos, por lo que su positivación tendrá un carácter constitutivo, y no declarativo solamente, dando vida a normas que regulan situaciones subjetivas, presupuesto lógico de todo derecho fundamental. En igual sentido, los derechos fundamentales pueden considerarse como la dimensión más avanzada del proceso de juridificación de los derechos humanos a partir de los textos constitucionales, condicionándose su ejercicio por la sanción de las normas jurídicas, de tal modo que pueden ser justiciables ante instancias jurisdiccionales. No obstante, este criterio ha sido objeto de intensos debates en la doctrina constitucionalista comparada, con respecto a identificar inequívocamente el carácter fundamental de los DESC, que, aun constitucionalmente reconocidos, se les ha dado un tratamiento jurídico diferenciado del resto.

Por demás, esta problemática en torno a la determinación inequívoca del carácter fundamental de los DESC no puede brindar respuestas satisfactorias si no se repasan inicialmente los elementos característicos ofrecidos por la doctrina constitucionalista alemana en la construcción teórica de los derechos fundamentales -recuérdese que la acuñación del término es un legado propio de la misma-, y que fueron expresados en la constitucionalización de los mismos, principalmente, a partir de la Constitución de Weimar, continuando con la Ley Fundamental de Bonn.

\footnotetext{
${ }^{12} \mathrm{Al}$ respecto, D’Estéfano PisAni (1988) p. 297, recuerda que la Asamblea General de las Naciones Unidas aprobó el 5 de febrero de 1952 la resolución 548 (VI), la cual dispone que todos los documentos de trabajo de las Naciones Unidas y las publicaciones que ella haga en lengua española, al considerar lo que se refiere a la Declaración Universal de Derechos Humanos y a los Pactos Internacionales respectivos deberán decir "derechos humanos".

13 Pérez Luño (1994) p. 46.
} 
En Weimar fueron constitucionalizados los derechos fundamentales en la Parte Segunda del texto magno, la cual estuvo, a su vez, subdividida en secciones, en las que se llegaron a reconocer formalmente como fundamentales algunos de los conocidos DESC (por ejemplo, en las Secciones II "De la vida social", IV "Educación y Enseñanza" y V "Vida económica" se llegó a regular un extenso catálogo de DESC, como los derechos a la maternidad, art. 119, a la educación de los hijos, art. 120, a la educación en sentido general, arts. 142-150, al trabajo, arts. $157-159$ y 163 , y a la seguridad social, art. 161, entre otros).

Sin embargo, persistió en la doctrina académica alemana de entonces una marcada influencia del modelo liberal de interpretación de los derechos fundamentales, pretendiendo considerar exclusivamente como tales, y absolutos en consecuencia, aquellos derechos de libertad del individuo frente al Estado, es decir, aquellos derechos civiles y políticos, siendo considerados los demás derechos constitucionales como relativos, al no disfrutar del mismo grado de protección que los primeros, quedando excluidos del la categoría fundamental los DESC y, en sentido general, relativizada su condición jurídica. Esta interpretación, condicionada además por el vacío jurisprudencial en torno a la identificación de los elementos definitorios de los derechos fundamentales, fue asumida por la doctrina académica, desde la cual se comenzaron a delimitar aquellas normas que contenían "auténticos" derechos fundamentales de aquellas otras que no los contenían.

Tales criterios condujeron a construir el modelo de interpretación de los derechos fundamentales de la garantía del instituto o garantía institucional, desde el cual se ponderaba que existían derechos indisponibles para el legislador, es decir, derechos fundamentales absolutos, y derechos que se encontraban a disposición del legislador, derechos fundamentales relativos. Todo ello partía de identificar el contenido esencial de los derechos, y con ello su individualización constitucional. ${ }^{14}$ En este sentido, siguiendo lo expuesto por César LANDA, se puede concluir que "a la luz del pensamiento institucional de los derechos fundamentales, es posible identificar el contenido esencial de los mismos, a partir de la idea de la libertad como instituto, es decir, como un dato objetivo que se realiza y despliega en la sociedad abierta; pero que se encuentra en los conceptos jurídicos diversos elementos que inciden directa o indirectamente en la formación, proceso y resultado de la norma constitucional". ${ }^{15}$

De este modo, este modelo de interpretación de los derechos fundamentales afirmó que los mismos "(...) en sentido propio son, esencialmente, los derechos

${ }^{14}$ Vid. Pérez Royo (1997) pp. 254 y ss.

${ }^{15}$ LANDA (2002) p. 62. 
del hombre individual libre y, por cierto, derechos que él tiene frente al Estado", tal y como lo significó Carl SCHMITT, ${ }^{16}$ marcándose así una diferencia sustancial y jerarquización entre los derechos individuales y los sociales, por cuanto fueron estimados estos últimos como que sólo comprendían principios objetivos, sin otro valor que el de un programa político y que, por tanto, nada tenían que ver con el Derecho. Por ende "todos los derechos fundamentales auténticos son derechos fundamentales absolutos, o sea, no se garantizan "con arreglo a las leyes", su contenido no resulta de la ley, sino que la injerencia legal aparece como excepción”. ${ }^{17}$

Posteriormente, el reconocimiento de los derechos fundamentales en la Ley Fundamental de Bonn permitió proyectar una construcción teórica de los mismos mucho más consolidada y madura, toda vez que ofreció otros elementos definitorios o caracterizadores de los mismos. Tales elementos se esbozaron en la doctrina alemana a partir de lo dispuesto constitucionalmente en los artículos 1 y 19 de la referida ley, significando uno de los aportes más trascendentales de la misma a la doctrina constitucionalista contemporánea. Entre éstos se enumeran, como elementos definitorios, amén de reafirmar el respeto del contenido esencial de los derechos (art. 19.2) -traducido en una cláusula general de protección jurisdiccional de los derechos fundamentales frente a las lesiones que pudieran venir de los órganos parlamentarios-, la eficacia directa de los mismos y la vinculación de éstos a los poderes públicos (art. 1.3), la indisponibilidad con relación al legislador (art. 19.1), ${ }^{18}$ así como el control judicial al que podrán ser sometidos, toda vez que cualquier titular de ellos podrá invocar las vías jurisdiccionales para su restitución (art. 19.4).

Por demás, nuevamente se incluían en la carta constitucional de derechos fundamentales, una serie de DESC, como los derechos a la familia (art. 6), a la educación (art. 7), al trabajo (art. 12), o la socialización de la propiedad (art. 15), entre otros, todos los cuales se les debió reconocer extensivamente la cualidad de fundamentales y, consecuentemente, la extensión de las garantías jurídicas para su defensa y protección validadas constitucional y legalmente.

Sin embargo, se expusieron criterios en la doctrina alemana contrario sensu a ello, posicionándose a favor de la minimización de los DESC, tal y como se

\footnotetext{
${ }^{16}$ Sснмітт (1927) p. 190.

${ }^{17}$ Ídem.

${ }^{18}$ Precisamente le corresponde a Peter HaberLe, según lo expuesto por LANDA (2002) p. 62, el protagonismo en desarrollar "la categoría de los límites del legislador en relación con los derechos fundamentales, reformulando la tesis de la reserva de ley y postulando la tesis central de contenido esencial Wesensgehattgarantie de los derechos fundamentales, como fórmula sintética que encierra el concepto de valor que se encuentra en cada derecho fundamental".
} 
impusiera una especie de antinomia entre éstos y los derechos civiles y políticos. ${ }^{19}$ Tal es así que TOMANDL ${ }^{20}$ consideró que el reconocimiento de los derechos de la segunda generación disminuía en su ejercicio a las libertades públicas, prevaleciendo el criterio, al parecer, de que "mientras más iguales pretendemos ser en la sociedad menos libres seremos y viceversa".

Empero, frente a estas posiciones absolutistas que, por demás, reducían el espacio de la libertad individual al de la libertad jurídica, ROBERT ALEXY ${ }^{21}$ advirtió la existencia de dos argumentos a favor de los DESC, que no deben ser, inicialmente, desconocidos a pesar de las reservas que se pueda tener con ellos: el primero alerta que “(...) la libertad jurídica para hacer u omitir algo sin la libertad fáctica (real), es decir, sin la posibilidad fáctica de elegir entre lo permitido, carece de todo valor", y el segundo avizora que "(...) bajo las condiciones de la moderna sociedad industrial, la libertad fáctica de un gran número de titulares de derechos fundamentales no encuentra su sustrato material en un "ámbito vital dominado por ellos", sino que depende esencialmente de actividades estatales". Con ello, Alexy eleva el valor de la libertad fáctica, exponiendo que "(...) los derechos fundamentales, si su objetivo es que la personalidad humana se desarrolle libremente, apuntan también a libertades fácticas, es decir, deben asegurar también los presupuestos del uso de las libertades jurídicas y, por lo tanto, son "normaciones no sólo para el poder hacer jurídico, sino también del poder actuar realmente"”.

Por demás, las anteriores postulaciones teóricas, émulas de la calificación de los derechos fundamentales a partir del grado de protección jurídica a que estaban sometidos, irradiaron inmediatamente en el acervo doctrinal europeo posterior a la Segunda Guerra Mundial, principalmente en España, donde el constituyente en 1978 fue mucho más detallado y sistematizó una clasificación de los mismos partiendo de las garantías que se quiso atribuir a cada uno de ellos, reconociendo una larga lista de derechos fundamentales con diferentes niveles de garantías (Título I), estructura de reconocimiento sin precedentes en el acontecer constitucionalista, incluso no seguido por su predecesora y fuente de indudable inspiración, la Ley Fundamental de Bonn.

Por ello, el modelo español de constitucionalización de los derechos fundamentales planteó problemas terminológicos sobre la caracterización de los derechos como "fundamentales". En este caso, un mero examen lingüístico de la terminología empleada en la Constitución en esta clasificación de los derechos,

${ }^{19}$ Cfr. Torrado (2003) pp. 56 y ss.

${ }^{20}$ Cit. Pérez Luño (1994) p. 204.

${ }^{21}$ Alexy (1993) pp. 486 y ss. 
al que nos invita Teresa FreIXES SANJUÁN, ${ }^{22}$ evidencia que el término "fundamentales" se ubica tanto en la caracterización general de todo el Título I como en la denominación de la mencionada primera sección. De este modo, el empleo de un lenguaje ambivalente y nada clarificante al positivar los derechos fundamentales, contribuyó notablemente a que la jurisprudencia constitucional española considerara exclusivamente como tales a aquellos que se postulaban con un mayor nivel de protección, es decir, a los encuadrados en la mencionada sección. Las garantías jurídicas previstas para estos "derechos fundamentales" serán, según lo dispuesto en el artículo 53, y evidenciando una cierta germanización del orden constitucional español: vinculación y eficacia directas, garantía de su contenido esencial, reserva de ley orgánica, tutela judicial preferente y sumaria, amparo constitucional y eficacia frente a terceros..$^{23}$

Consecuentemente, el resto de los derechos constitucionalmente reconocidos, donde se presenta un extenso catálogo de DESC concebidos como Principios Rectores de la Política Social y Económica en el Capítulo Tercero del referido Título, no deberán ser considerados con el valor de fundamentales. Esta posición ha quedado reafirmada en las doctrinas jurisprudencial y académica españolas, defendiéndose, casi por unanimidad y prácticamente de forma pacífica, el criterio de que estos derechos, tal y como están configurados constitucionalmente, constituyen normas programáticas, demandados de configuración legal para su completa y adecuada protección. Por demás, afirman el punto de vista de que sólo los derechos que tienen como contenido esencial la libertad deberán ser considerados como fundamentales, por tratarse de verdaderos derechos subjetivos.

El eje en torno al cual gira este modelo de interpretación está expuesto en la Sentencia No 25 de 1981 del Tribunal Constitucional español, donde se declara, en una primera parte, que "los derechos fundamentales son derechos subjetivos, derechos de los individuos no sólo en cuanto derechos de los ciudadanos en sentido estricto, sino en cuanto garantizan un "status" jurídico o la libertad en un

\footnotetext{
${ }^{22}$ Freixes Sanjuán (1992) p. 94.

${ }^{23}$ Cuestionable aún es la materialización jurídica plena de la eficacia frente a terceros de los derechos fundamentales en el ordenamiento español, toda vez que si bien la Constitución española dispone en su artículo 9 que todos los ciudadanos y los poderes públicos se encuentran sujetos a la Constitución y al resto del ordenamiento jurídico, no es menos cierto el hecho de que el recurso de amparo, vía por excelencia en la defensa de los derechos fundamentales, no se configura frente a la acción de los particulares, según lo dispuesto en el artículo 41.2 de la Ley Orgánica 2 de 3 de octubre de 1979, del Tribunal Constitucional. No obstante, es menester mencionar que los conflictos suscitados entre particulares se dilucidan ante los tribunales ordinarios, según lo previsto para el "amparo judicial", concebido a partir de lo dispuesto en la Constitución, en la primera parte del art. 53.2, y en la Ley 62 de 26 de diciembre de 1978, de protección jurisdiccional de los derechos fundamentales de la persona.
} 
ámbito de existencia”. ${ }^{24}$ No obstante, a continuación se evoca que los derechos fundamentales, "al propio tiempo, son elementos esenciales en un ordenamiento objetivo de la comunidad nacional, en cuanto ésta se configura como marco de una convivencia humana justa y pacífica, plasmada históricamente en el Estado de Derecho, y más tarde en el Estado Social de Derecho o el Estado Social y democrático de Derecho, según la fórmula de nuestra Constitución”. ${ }^{25}$ Con ello, debe permitirse apreciar que los DESC son pilares fundamentales y básicos de todo Estado que se proclame con carácter Social, no hacerlo sería desconocer la voluntad del constituyente de 1978 y, con ello, el de la voluntad del titular originario de la soberanía: el pueblo español.

En este último sentido, y con el ánimo de rescatar el valor fundamental de los DESC, se ha pronunciado en la propia doctrina FreIXES SANJUÁn, ${ }^{26}$ sosteniendo el deber de concederles, o más bien reconocerles, ese valor a todos estos DESC puesto que no les falta protección jurídica $y$, aunque la que obtienen es menor que la que hubieran obtenido si la Constitución les hubiera otorgado la estructura de plenos derechos subjetivos, su estructura como orden de valores y el acceso a determinadas y muy importantes garantías constitucionales les atribuyen carácter jurídico de derechos fundamentales, sin que quepa hacer distinción de rango en base a su efectividad inmediata o diferida.

Además, no debe obviarse en un estudio que pretenda acercarse al orden constitucional de los derechos fundamentales en España, el hecho de que en la propia Sección $1^{a}$ queda reconocido en el artículo 27 el derecho a la educación, por lo que sujetándose a la interpretación predominante en la doctrina española, este DESC estaría sujeto a todas las garantías jurídicas expresadas en la Constitución española, entre las que, recuerdo, estarían su vinculación y eficacia directas, así como el acceso al amparo constitucional, elementos configuradores en torno a los cuales ha girado el discurso minimizador del carácter de fundamental de los DESC, toda vez que se entiende que los mismos no puedan beneficiarse de tales elementos configuradores.

En sentido contrario, en otros ordenamientos jurídicos se han reconocido con igual valor de fundamentales tanto derechos de la primera como de la segunda generación histórica. Con relación a ello, por ejemplo, ni la Constitución griega de 1975 hizo distinción notable entre los derechos de la primera y segunda generaciones, incluyéndolos a todos en su segunda parte titulada "Derechos individuales y fundamentales", ni la portuguesa de 1976, que, aunque distingue entre derechos

\footnotetext{
${ }^{24}$ Tomado de Asensi Sabater (1996) p. 119.

${ }^{25}$ Ídem.

${ }^{26}$ Freixes Sanjuán (1992) pp. 91 y ss.
} 
individuales y sociales, incluye a ambos en su primera parte "De los derechos y deberes fundamentales". De hecho, la Constitución portuguesa proscribe la negación del acceso a la justicia ordinaria en defensa de los derechos fundamentales por alegarse insuficiencia de medios económicos, en lo que sin dudas significa un espaldarazo a los DESC (art. 20.1). Mientras la Constitución helénica, por su parte, llega a afirmar que el reconocimiento y la protección de los derechos fundamentales e imprescriptibles del hombre por el Estado tienen por objeto la realización del progreso social en la libertad y la justicia (art. 25.2), en lo que puede evaluarse de visión armónica en la concepción de los mismos.

En este orden, cabe destacar uno de los referentes más interesantes en cuanto a la juridificación de los derechos fundamentales en América latina, como lo es el caso del ordenamiento constitucional venezolano, donde desde la Constitución de 1961, llegando a la actual Constitución de 1999, se han reconocido con el mismo rango de protección y defensa jurídicas los DESC, no destacando el presunto valor absoluto o relativo que pudiera diferenciar algunos derechos con relación a otros.

De hecho, la Constitución de 1961 consagró un amplio catálogo de DESC, ofreciendo amplias posibilidades para la justiciabilidad de los mismos. Así, en su Título III, denominado "De los Deberes, Derechos y Garantías", dispuso que los tribunales de justicia ampararían a todo habitante del país en el goce y ejercicio de los derechos y garantías que la Constitución establecía, conforme a la ley. Con ello, quedó extendido el amparo constitucional, previsto en el artículo 49, a todos los derechos comprendidos en el mencionado Título, entre los que se encontraban los DESC (ubicados en el Capítulo IV).

Con la promulgación en 1988 de la Ley Orgánica de Amparo sobre Derechos y Garantías Constitucionales -demasiado tardía, lo que pudo conducir a que los órganos judiciales se manifestaran renuentes a aceptar la invocación del amparo constitucional en los supuestos de presuntas violaciones o amenazas al ejercicio y goce pleno de los DESC reconocidos constitucionalmente, y, con ello, la desprotección efectiva de los mismos- se dispuso, definitivamente, que toda persona natural habitante de la República, o persona jurídica domiciliada en ésta, podría solicitar ante los órganos judiciales el amparo constitucional, previsto constitucionalmente, para el goce y el ejercicio de todos los derechos y garantías previstos en la Carta Magna, sin desconocer o jerarquizar alguno.

Posteriormente, tales posiciones normativas fueron reafirmadas por la vigente Constitución de 1999, en la que, de igual modo, se prescribió entre las disposiciones generales de su Título III, "De los derechos, humanos y garantías, y de los deberes" la posibilidad de acceder a los órganos judiciales para hacer valer sus derechos e intereses, inclusive los colectivos o difusos (tutela efectiva o amparo 
judicial), así como al amparo constitucional frente a cualquier amenaza o lesión al goce o ejercicio de cualquier derecho reconocido o garantizado en el propio texto, incluso de otros que aún sin estarlo son inherentes a la persona humana, dejando pautada la "carta blanca" de derechos fundamentales (art. 27). De hecho, este último término, "derechos fundamentales", no fue utilizado por los constituyentes de 1961 ni de 1999, induciendo a pensar en que no deseaba manifestarse una voluntad o intención que comprometiera una jerarquización o elevación de los derechos reconocidos constitucionalmente con relación a otros, que sí lo fueran en el resto del ordenamiento jurídico nacional o en el Derecho Internacional, invocándose una marcada influencia ius naturalista en esta visión.

En definitiva, esta concepción de los derechos fundamentales, donde no se jerarquizan o minimizan algunos en virtud de su grado de protección o garantía jurídica, ya que todos son en alguna medida tutelados, marcó una tendencia evidenciada en los posteriores procesos constituyentes acaecidos en el área latinoamericana. En estos supuestos, como en los casos recientes de Ecuador y Bolivia que culminaron con la promulgación de sendos textos constitucionales en el año 2008.

En el primero de ellos, incluso, se llegó a afirmar, en su artículo 11.3, que:

"Los derechos y garantías establecidos en la Constitución y en los instrumentos internacionales de derechos humanos serán de directa e inmediata aplicación por y ante cualquier servidora o servidor público, administrativo o judicial, de oficio o a petición de parte.", asi como que: "Los derechos son plenamente justiciables. No podrá alegarse falta de norma jurídica para justificar su violación o desconocimiento, para desechar la acción por esos hechos ni para negar su reconocimiento".

Incluso se extienden, por igual, las garantías normativas y jurisdiccionales (acción de protección) a todos los derechos constitucionalmente reconocidos, entre los que aparece un detallado y extenso catálogo de DESC.

Con relación a la actual Constitución boliviana, en ésta se denomina el Capítulo Segundo, de su Título II, "Derechos Fundamentales", cuando a continuación, en los subsiguientes Capítulos del propio apartado, los comienza a denominar según su contenido como "Derechos Civiles y Políticos", "Derechos de las naciones y los pueblos indígena originario campesinos", "Derechos sociales y económicos", "Educación, Interculturalidad y Derechos Culturales" y, finalmente, "Comunicación Social”, en lo relacionado con el reconocimiento de derechos. Empero, en su artículo 13, apartado III, enuncia expresamente que de la clasificación de los derechos que aparecen en la Constitución no deberán entenderse jerarquización alguna ni superioridad de unos sobre otros. En definitiva, entre los que se incluyeron como "fundamentales", en este Capítulo en particular, se encuentran aquellos que tienen un marcado significado político y social en la sociedad boliviana, bien 
por los déficits históricos en su atención o reconocimiento, lo que ha marcado una minusvalía jurídica en su efectivo ejercicio y goce por parte de los titulares de los mismos, o bien por la proyección con que el nuevo Estado nacional pretende construirse, máxime conociéndose con antelación los marcados lastres sociales acumulados en ese país. Por ello, quizá, aparecen derechos regulados en este apartado que discurren desde los de contenidos civil o político, pasando por los de ámbito económico, social y cultural, y hasta los de solidaridad. Pero lo cierto es que igual tratamiento reciben todos los derechos reconocidos, en relación con las garantías jurídicas, a partir de lo dispuesto en el Título IV.

Esta tendencia invita a plantearse la posibilidad real, inmediata o diferida, de justiciabilidad de los DESC, lo que era insostenible desde la doctrina o praxis jurídica de antaño, pero que con mayores argumentos se demanda en la actualidad, emplazando la inanición pública con relación al aseguramiento mínimo de los mismos, con el propósito de hilvanar sus plenos goce y disfrute, los que deben coadyuvar al desarrollo pleno e integral de la personalidad humana. Con relación a los contenidos esenciales, en cuyos contornos puede efectuarse dicha justiciabilidad, se evidencian imprecisos a partir de los asegurados constitucionalmente, ya que en no todos los textos se llegan a reconocer los mismos contenidos, lo que permitiría desdibujar inequívocamente el alcance de la efectividad inmediata de estos derechos y, con ello, el ejercicio inmediato por parte de sus titulares.

\section{LOS DERECHOS ECONÓMICOS, SOCIALES Y CULTURALES EN LA CONSTITUCIÓN Y EN EL ORDENAMIENTO JURÍDICO CUBANOS}

En relación al ordenamiento jurídico cubano, la inicial problemática que arroja, obviamente, la propia formulación constitucional de los DESC en el texto de 1976 es la indeterminación del objeto de regulación de algunos de ellos y, consecuentemente, la irreconocibilidad del contenido esencial, cual garantía dirigida a salvaguardar el "núcleo duro" de los mismos, déficit que puede repercutir negativamente en la determinación de los límites en su ejercicio por parte de sus titulares y en su consecuente efectividad jurídica. Tal situación queda agravada ante la ausencia de una normativa de ordenación general de los DESC, que estipule tales contenidos esenciales mínimos, o de una jurisdicción constitucional en nuestro ámbito nacional, quedando prácticamente en la Asamblea Nacional del Poder Popular, o más bien en el Consejo de Estado, la posibilidad de determinar tales contornos siguiendo la facultad atribuida por la Constitución (art. $90 \mathrm{ch}$ ) de interpretar, de manera general y obligatoria, las leyes vigentes, en caso de ser necesario, o bien promulgando una legislación complementaria de desarrollo respectivamente. 
En relación a las garantías jurídicas dirigidas a la defensa y protección de los DESC prescriptas constitucionalmente, debe precisarse que al constitucionalizarse las garantías de los referidos derechos en el texto constitucional, denominándose el Capítulo VII como Derechos, Deberes y Garantías Fundamentales, más bien se positivaron las condiciones materiales imprescindibles para la realización de los mismos, no así con las vías dirigidas a la defensa jurídica de los derechos. ${ }^{27}$ Precisamente en este ámbito de la problemática de los derechos fundamentales constitucionalmente reconocidos en Cuba es hacia donde más se dirigen los debates por un considerable sector de la doctrina nacional en la actualidad. ${ }^{28}$

Sin embargo, aunque expresamente no fueran consignadas en el referido Capítulo las garantías para la defensa jurídica de los derechos fundamentales, y con ello de los DESC, puede constatarse en la legislación ordinaria unos instrumentos procesales que pueden activarse en el supuesto de vulneración de los derechos fundamentales, ${ }^{29}$ y que en el caso concreto de los DESC se verifican del modo que a continuación se expone:

- Las garantías jurisdiccionales generales u ordinarias: al no establecerse en nuestro ordenamiento jurídico procedimientos jurisdiccionales exclusivamente dirigidos a tutelar los derechos fundamentales, ya sea ante órganos jurisdiccionales ordinarios o extraordinarios, serán, precisamente, a través de los procedimientos jurisdiccionales ordinarios que se protegerán los derechos fundamentales reconocidos en el texto constitucional. Estas garantías no se encuentran previstas expresamente en el articulado constitucional, no obstante lo cual para algunos autores nacionale ${ }^{30}$ de la lectura de algunos artículos puede inferirse la alusión a ellas, como

\footnotetext{
${ }^{27}$ Para Villabella Armengol (2000 a) p. 320, se utilizó injustificadamente el término "garantías" por no exponerse ninguno de los mecanismos que la dogmática constitucional moderna considera como tal, criterio que no asumo pues si bien se consignó exclusivamente la condicionalidad material, bien pudieron incluirse expresamente las garantías jurídicas, pues una no excluye a la otra. Además, es válido recordar que la visión imperante en la dogmática comparada sobre las garantías es eminentemente procesalista o judicialista, por lo que tampoco dan una respuesta cabal o definitiva a la problemática de los derechos fundamentales a la cuestión de sus garantías.

${ }^{28}$ Vid. Villabella Armengol (2000 a) pp. 319 y ss.; Cutié Mustelier, Mariño Castellanos y Méndez López (2000) pp. 324 y ss., Cutié Mustelier, Mariño Castellanos y Méndez López (1998) pp. 151 y ss.; y TORRADO (2003) pp. 227 y ss.

${ }^{29} \mathrm{Al}$ respecto, vid. Villabella Armengol (2000 a) p. 321; Cutié Mustelier, Mariño Castellanos y Méndez López (2000) pp. 324 y ss., y Cutié Mustelier, Mariño Castellanos y Méndez López (1998) pp. 151 y ss; y ToRRADo (2003) pp. 227 y ss. Para más detalles sobre el sistema de protección jurídica de los derechos fundamentales en Cuba, vid. Cutié Mustelier (1999) pp. 77 y ss.; y Cutié Mustelier y Méndez López (2006) pp. 1 y ss.

${ }^{30}$ Cutié Mustelier, Mariño Castellanos y Méndez lópez (2000) pp. 328 y 330, y Cutié Mustelier, Mariño Castellanos y Méndez López (1998) p. 153; y Torrado (2003) p. 231.
} 
del artículo 26, cuando se refiere al derecho que toda persona tiene a reclamar y obtener la correspondiente reparación o indemnización que establezca la ley cuando sufriera un daño o perjuicio causado indebidamente por un agente o funcionario del Estado con motivo del ejercicio de sus funciones. Estas garantías hallan su fundamento tradicional en el derecho que le asiste a toda persona de presentar un recurso efectivo ante los órganos judiciales respecto de la posible vulneración de sus derechos fundamentales, consignado en los instrumentos internacionales de protección de éstos ${ }^{31} \mathrm{o}$, expresamente, en algunos ordenamientos jurídicos en los propios textos constitucionales. Su ausencia redundaría en la "esterilidad" de la defensa jurídica de los derechos fundamentales.

Con respecto a Cuba, podemos fundamentar jurídicamente la existencia de estas garantías en la vigente legislación de organización del sistema judicial. Así, en la Ley No 82 de 11 de julio de 1997, Ley de los Tribunales Populares, ${ }^{32}$ se establece en el inciso c del artículo 4, entre los principales objetivos de la actividad judicial, el de "amparar la vida, la libertad, la dignidad, las relaciones familiares, el honor, el matrimonio, y los demás derechos e intereses legítimos de los ciudadanos".

Entre estas garantías pueden ser instadas en la defensa de los DESC:

- El procedimiento administrativo (conocido en el Derecho comparado como procedimiento contencioso-administrativo): la regulación de este procedimiento aparece en la Ley No 7 de 19 de agosto de $1977,{ }^{33}$ recientemente modificada por el Decreto-Ley No 241 de 26 de septiembre de 2006,,34 a partir del cual se comenzó a denominar Ley de Procedimiento Civil, Administrativo, Laboral y Económico (LPCALE). Según lo dispuesto en su artículo 656, mediante este procedimiento pueden impugnarse todas las disposiciones de carácter general y resoluciones que emanen de los organismos de la Administración Central del Estado, sus delegaciones territoriales y los órganos de la administración local, que vulneren derechos legalmente establecidos a favor del reclamante, salvo lo dispuesto en los artículos 657 y 673 .

Con relación a este procedimiento como vía para la defensa jurisdiccional de los derechos fundamentales en nuestro país, Cutié Mustelien ${ }^{35}$ ha expuesto

\footnotetext{
${ }^{31}$ Tal como consigna la Declaración Universal de los Derechos Humanos en su artículo 8, de la que Cuba es signataria.

${ }^{32}$ G.O. Extraordinaria No 8 de 14 de junio de 1997.

${ }^{33}$ G.O. de 20 de agosto de 1977.

${ }^{34}$ G.O. Extraordinaria de 27 de septiembre de 2006.

${ }^{35}$ Cutié Mustelier (1999) pp. 86 y ss.
} 
entre sus ventajas, el que su ámbito protector abarca cualquier derecho, siempre y cuando el titular tenga la condición de administrado y la lesión provenga de la Administración Pública o de sus agentes, y el efecto anulador de la sentencia estimativa que podrá revocar total o parcialmente la disposición o resolución impugnada (artículos 690 y 691, LPCALE). Por otra parte, advierte como una de sus mayores desventajas el que de su ámbito protector queden excluidos las cuestiones en materias constitucionales ${ }^{36} \mathrm{y}$ el ejercicio de la potestad discrecional (artículo 657, incisos 4 y 6, LPCALE).

No obstante, se torna válido apuntar que ese procedimiento deja expedita una vía para la defensa jurídica de los DESC frente a las actuaciones de la Administración Pública que puedan lesionar, vulnerar, amenazar o disminuir su ejercicio por parte de sus titulares, vía recurrible por excelencia toda vez que en nuestro país tiene una alta incidencia la Administración Pública en relación con la regulación y disposición de los mismos, por lo que emana de la misma la ordenación jurídica fundamental de éstos.

En sentido general, toda disposición administrativa debe ser susceptible de impugnación judicial cuando afecte a los derechos fundamentales e intereses legítimos consagrados constitucionalmente, sin que pueda producirse indefensión para sus titulares, salvo las excepciones expresamente consignadas en la LPCALE. De lo contrario, aceptar que no sean revisables en sede judicial las decisiones administrativas que presumiblemente vulneren el ejercicio de derechos fundamentales sería incentivar en nuestra sociedad zonas al margen del Derecho, donde pudieran efectuarse potenciales arbitrariedades por parte de las autoridades administrativas.

- El procedimiento laboral, el que pudiera antojarse en nuestro Derecho de ser la vía efectiva por excelencia en garantizar jurídicamente el disfrute y ejercicio de los derechos laborales. El procedimiento laboral vigente quedó dispuesto a partir de lo establecido en el Decreto-Ley No 176 de 15 de agosto de 1997, el que estableció la solución de los conflictos o litigios en el ámbito laboral que estuviesen fundados en la imposición de medidas disciplinarias o en el reconocimiento, concesión y

\footnotetext{
${ }^{36}$ Con respecto a las "materias constitucionales", la formulación en la ley de una manera general y amplia de esta expresión suscita dudas en torno a considerar si las reclamaciones sobre derechos reconocidos en la Constitución pueden o no instarse ante la vía jurisdiccional administrativa. En el supuesto de negarles esta vía a las pretensiones que se deduzcan contra las disposiciones de carácter general y resoluciones que emanen de la Administración, y que en ambos casos supongan la vulneración de derechos legalmente reconocidos a favor del reclamante, se entraría en contradicción con lo preceptuado en la propia ley en su artículo 656 inciso primero. En tal sentido, con el propósito de aclarar esta situación, CuTié Mustelier (1999) p. 87, sostiene el criterio, que comparto, de que "el sentido del legislador no era excluir tal materia sino las relativas a las cuestiones de constitucionalidad de leyes y demás disposiciones de carácter general, para lo cual se debe seguir el procedimiento establecido ante la Asamblea Nacional del Poder Popular”.
} 
reclamación de las obligaciones y de los derechos emanados de la legislación laboral, complementaria de lo dispuesto constitucionalmente, entre otras motivaciones. Entre estos últimos pueden referirse los conflictos en materia salarial, de mejor empleo, y de seguridad social a corto plazo, es decir, subsidios por enfermedad o accidente común, subsidio por enfermedad profesional o accidente del trabajo, licencia de maternidad y pensión por invalidez parcial, entre otros. Los litigios laborales, en este ámbito, podrán suscitarse ante los Órganos de Justicia Laboral de Base (OJLB), constituidos en las entidades laborales como órgano primario y de carácter obligatorio en la solución de algún conflicto laboral, y ante los Tribunales Municipales Populares. La Sala de lo Laboral de Tribunal Supremo Popular conocerá directamente de las solicitudes de procedimientos de revisión contra las sentencias firmes de los anteriores tribunales presentadas por algún titular de un derecho laboral que lo considere afectado.

- El procedimiento penal, que puede ofrecer tutela penal a ciertos DESC al quedar tipificados en el actual Código Penal, Ley No 62 de 29 de diciembre de 1987, como conductas delictivas y punibles, acciones u omisiones que lesionen o menoscaben la salud pública (Capítulo V, arts. 187 al 199) y los derechos laborales (Capítulo X, arts. 296 al 297), aunque el alcance material de tales preceptos se circunscribe muy particularmente a determinados contenidos de estos derechos.

Por otra parte, con relación a las garantías no jurisdiccionales, identificadas en nuestra doctrina por Pérez Hernández y PRIETO VALDÉS ${ }^{37}$ como garantías institucionales, por cuanto "(...) comprenden a los órganos e instituciones ante los que se presentan las reclamaciones por presuntas lesiones de derechos, y que en ocasiones tienen entre sus atribuciones la facultad de adoptar las decisiones que solucionen y permitan su reconocimiento, restitución, e indemnización, si fuere el caso". En nuestro ordenamiento jurídico se concretan en la queja ante la Fiscalía General de la República o sus dependencias territoriales y la queja administrativa. Su fundamento constitucional radica en el artículo 63 de la Constitución, si bien éste no agota toda la dimensión constitucional del derecho de queja y petición. Por otra parte no entraña una solución totalmente efectiva por cuanto el enunciado constitucional prevé exclusivamente el derecho a recibir la atención o respuestas pertinentes en un plazo adecuado, pero nada con respecto a la satisfacción de la pretensión expuesta.

En el supuesto de la queja tramitada ante la Fiscalía General de la República (FGR) o ante sus instancias territoriales, ésta se formula ante la Dirección de Protección a los Derechos de los Ciudadanos o ante sus respectivas dependencias

${ }^{37}$ Pérez Hernández y Prieto Valdés (2000) p. 304. 
territoriales. Esta función, íntimamente relacionada con la función atribuida constitucionalmente a la FGR en el art. 127 constitucional de velar, entre otros objetivos, por el control y la preservación de la legalidad, sobre la base de la vigilancia del estricto cumplimiento de la Constitución, las leyes y demás disposiciones legales, por los organismos del Estado, entidades económicas y sociales y por los ciudadanos, asimila a la FGR en nuestro Derecho, en alguna medida, a una institución similar del ombudsman escandinavo o Defensor del Pueblo, denominación esta última con la que se ha internacionalizado. ${ }^{38}$

Esta vía se desarrolla en la Ley No 83 de 13 de julio de 2000, de la Fiscalía General de la República, específicamente en su Capítulo III, denominado Protección de los Derechos Ciudadanos, y su fundamento legal aparece entre los objetivos de la FGR, mencionados en el art. 7 del propio texto legal, inciso c, cuando enuncia que la actividad de este órgano tiene como objetivo, entre otros, proteger a los ciudadanos en el ejercicio legítimo de sus derechos e intereses. En el referido Capítulo, en su único artículo, el 24, se establece que el Fiscal designado al efecto debe atender, investigar y responder en el plazo de sesenta días las denuncias, quejas y reclamaciones que en el orden legal formulen los ciudadanos. En el caso de apreciar alguna violación en el ejercicio de un derecho dispondrá, mediante resolución, que se restablezca la legalidad, tornándose, indudablemente, en una vía posible para exigir la restitución de un derecho fundamental lesionado, en este caso de alguno de los DESC consagrados en nuestro ordenamiento jurídico.

Por su parte, la queja administrativa, prevista en el art. 52 inciso r) del DecretoLey No 67 de 19 de abril de 1983, de Organización de la Administración Central del Estado, ${ }^{39}$ junto con el procedimiento jurisdiccional administrativo condensa la justicia administrativa en nuestro país. Según lo prescripto en el mencionado artículo, los organismos de la Administración Central del Estado tienen, entre sus deberes, atribuciones y funciones comunes, el de prestar atención y dar respuestas pertinentes, dentro de un término de sesenta días, a las quejas y peticiones que les dirijan los ciudadanos, debiéndose esforzar por resolver correctamente las cuestiones en ellas planteadas y adoptar las medidas para eliminar las deficiencias señaladas. Esta vez, al tratarse de un recurso administrativo interno, algunos autores nacionales al exponer sus principales desventajas, ${ }^{40}$ han enfatizado como principal

\footnotetext{
${ }^{38}$ Sobre la consideración de la FGR como un ente con funciones similares al del ombudsman escandinavo, cfr. Villabella Armengol (2000 a) p. 321; Cutié Mustelier, Mariño Castellanos y Méndez López (2000) p. 332; y TORRADO (2003) pp. 233 y ss.

${ }^{39}$ G.O. de 19 de abril de 1983.

${ }^{40}$ Cutié Mustelier, Mariño Castellanos y Méndez lópez (2000) pp. 331, Cutié Mustelier, Mariño Castellanos y Méndez López (1998) p. 154.
} 
insuficiencia del mismo el autocontrol que ejerce la propia Administración. Sin menoscabo de lo anterior, es válido referir que un considerable contraproducente de esta vía de tramitación de presuntas violaciones a los derechos fundamentales es el desconocimiento que pueda tener de él la ciudadanía, al no estar comprendido concretamente en la normativa constitucional o en una norma de dominio y conocimiento general de la misma, como pueda ser una normativa específica dirigida a la defensa jurídica de los reiterados derechos por parte de sus titulares, la cual no ha sido objeto de promulgación.

Finalmente, pueden apreciarse las garantías normativas o abstractas, considerando como tales aquellas instituciones comprendidas en la Constitución destinadas a enfrentar preventivamente las presuntas violaciones de los derechos fundamentales por parte de los órganos públicos. En el texto constitucional cubano puede apreciarse que se prevé la rigidez constitucional expuesta en el art. 137 segundo párrafo. Prevista para todos los derechos constitucionalmente reconocidos, en el mencionado artículo se establece un procedimiento de reforma que exige en el supuesto de referirse a los derechos constitucionalmente reconocidos, además de la mayoría cualificada de $2 / 3$ partes del voto de sus diputados efectuado en votación nominal, de la ratificación por el voto favorable de los ciudadanos con derecho electoral mediante un referendo aprobatorio. Se configuran así los derechos constitucionales como contenidos especialmente protegidos.

Con relación a la directa e inmediata aplicabilidad de la normativa constitucional que regula los derechos fundamentales, subsumida en el debate doctrinal sobre la directa aplicabilidad del texto constitucional -aún no agotado y, por momentos, evitado-, ${ }^{41}$ expresamente no se verifica ningún mandato constitucional que haga

\footnotetext{
${ }^{41}$ Según lo expuesto por Fernández Salgado (s.f.) p. 169, la Constitución cubana "no es norma de aplicación directa, requiere de leyes complementarias para su desarrollo y aplicación; es una norma, principio guía, que no vincula directamente a los operadores del derecho en su actuar", criterio contra el que me pronuncio contrario, puesto que, por una parte, no está validado positivamente en nuestro ordenamiento jurídico, mucho menos no existe mandato constitucional contrario a la directa aplicabilidad del texto constitucional, al menos en lo referente a los derechos fundamentales, por lo que los componentes sociales, bien sean los operadores jurídicos, están obligados a cumplir sus postulados desde el momento de promulgación del propio texto constitucional. Por otra parte, tampoco se verifica en la voluntad del constituyente tal consideración, o en la de la dirigencia política del país ocurre lo mismo, constatándose por el contrario una posición consecuente con la directa aplicabilidad. En este sentido, Prieto VAldés (2004) p. 44, recuerda: "La efectividad de los postulados constitucionales es un objetivo esencial en la sociedad. Ha de posibilitarse que actúen como parámetros conductuales, por lo cual los operadores jurídicos, en su quehacer diario, volverán su vista hacia sus normas a la hora de aplicar las disposiciones infla-constitucionales", y más adelante: "Debe asimismo entenderse que la Constitución es fuente directa de Derecho para todo proceso; que su aplicación preferente debe realizarse en materia de derechos constitucionales a falta de ley de desarrollo (...)". Finalmente, el argumento de la influencia del constitucionalismo socialista de entonces recurrido para validar la idea de la diferida aplicación de la
} 
referencia a la misma. ${ }^{42}$ Consecuentemente, la cuestión de la directa e inmediata aplicabilidad de los mandatos constitucionales que preceptúan el reconocimiento de los derechos fundamentales se encuentra indisolublemente relacionada con el grado de eficacia jurídica que de los mismos se haya reconocido por el Derecho. Desde mi punto de vista, he reiterado en otras oportunidades que no me cabe la menor duda de que las normas constitucionales que reconocen a los derechos fundamentales, expresan verdaderos mandatos preceptivos, y consecuentemente son directamente aplicables y exigibles, cual carácter sustancial de los mismos que no lo van a diferenciar del resto de los derechos positivados en el ordenamiento jurídico y del lugar que ocupan en la sociedad.

De no objetarse lo anterior, la Constitución cubana deberá ser considerada fuente directa de los derechos fundamentales que regula, no precisando de legislación complementaria de desarrollo para ser defendibles y justiciables, sí para su imprescindible materialización en el ordenamiento jurídico vigente con el objetivo de hacerlos más efectivos y precisos socialmente, lo cual es otra cuestión. Así, la posición de absoluta preeminencia que en el Derecho tienen las normas constitucionales que reconocen los derechos fundamentales significará la primera garantía, aunque no absoluta, para efectuar el ejercicio de los derechos fundamentales por parte de sus titulares. Con ello, reafirmaríamos el valor jurídico de fundamentales de los DESC en nuestro ordenamiento nacional.

\section{A MOdO DE CONCLUSIONES \\ (O EL RECURSO PARA EL DEBATE IMPOSTERGABLE)}

Arribado a este punto es válido puntualizar lo que se ha querido evidenciar intencionalmente durante el transcurso de este estudio: la principal problemática para determinar el carácter fundamental de los DESC, y con ello sus necesarias y debidas defendibilidad y justiciabilidad, está fundada consecuentemente en la relativamente poca construcción doctrinal en torno a los mismos, que presente

Constitución cubana, no es absoluto, pues todo lo contrario se puede apreciar en el enunciado del art. 105 de la Constitución alemana de 1968, cuando estableció que: "La Constitución es fuente directa de Derecho", mención expresa que si bien no fue común en el modelo constitucional socialista significa una ruptura esencial con aquella línea de pensamiento. En torno a la eficacia normativo-jurídica de la Constitución cubana, vid. Mondelo García (2006) pp. 18 y ss.

${ }^{42}$ A propósito de esta consideración con respecto a la aplicabilidad directa de las normas constitucionales, PRieto VAldés (2002) p. 137, sostiene que “(...) ni el legislador cubano constituyentista ni el ordinario han establecido límites a la aplicabilidad directa de la normativa constitucional, sino que por el contrario fue así concebida, aun cuando como consecuencia de problemas de prácticas jurídicas y de decisión más que de prohibición, no goza de eficacia normativa directa, dependiendo de la realización de sus postulados del accionar del órganos supremo del poder estatal". 
y plantee inequívocamente su dogmática particular, toda vez que la positivación a que han sido sometidos ha estado influida en disímiles y distantes lógicas y fundamentos.

Desde mi punto de vista, considero que todos los derechos reconocidos constitucionalmente debe considérarse, en un principio, con el mismo valor jurídico de fundamentales, pudiendo diferenciarse por el grado de protección jurídica destinado a los mismos en el ordenamiento jurídico respectivo. De tal modo, deben delimitarse dos cuestiones diferentes: el reconocimiento (existencia) de un derecho y, por otra parte, el grado de protección que recibe el mismo. Tal y como afirmara CAMPS I POVILL: "La inexistencia de un plus en su protección no trae como consecuencia la negación del derecho, ya que son elementos jurídicos de diferente ámbito. Una cosa es el derecho y otra su nivel de garantía, y la imposibilidad de que sea directamente exigible no hace inexistente el derecho". ${ }^{43}$

Además, no debe obviarse que los DESC representan un catálogo de exigencias que la consecución plena de la dignidad de la persona humana impone en la actualidad a toda organización jurídico-política, al igual que los derechos civiles y políticos. Por tanto, al margen de cualquier pretendida jerarquización teniendo en cuenta su nivel de juridificación, éstos deben ocupar el lugar que merecen por su condición reconocida en los respectivos ordenamientos jurídicos: el de derechos fundamentales.

En ese sentido deben ser predicados perfecta e inequívocamente como derechos fundamentales, siendo exigible también tal consideración dentro de los cauces de institucionalización jurídica de los ordenamientos positivos. Pero este aspecto no es el decisivo, puesto que el vigor y eficacia que tienen atribuidos no le corresponden por reunir exclusivamente los rasgos técnicos característicos de los derechos subjetivos, sino por ser derechos reconocidos a todos los seres humanos. Obviamente podrán configurarse como derechos subjetivos en la medida que se les valide tal condición en los respectivos ordenamientos jurídicos y ello hará su eficacia mucho más relevante y "efectiva".

Consecuentemente, su eficacia jurídica dependerá de las concretas posibilidades reales de ejercicio y protección jurisdiccional con que cuenten dentro de los ordenamientos jurídicos, y su concreción material estará directamente relacionada con las condiciones sociales, económicas y políticas que se les brinden efectivamente en cada sociedad, por lo que, de carecer las mismas de tales, serían incapaces de posibilitar la realización plena de estos derechos.

En este sentido, el condicionamiento material de los DESC, asegurado por el régimen político, económico y social imperante en cada sociedad, estará dirigido

${ }^{43}$ Camps i Povill (1993), p. 27. 
a concretar el ejercicio real del derecho por parte de sus titulares con el objetivo de garantizar su pleno disfrute por parte de los mismos. Se torna, de este modo, como una garantía por excelencia de estos derechos que, sin embargo, no ha tenido la merecida consideración en la doctrina comparada, por lo que también deberá merecer mejor suerte y atención por parte de los constitucionalistas.

Finalmente, propongo reafirmar la noción de que deben delimitarse objetiva y concretamente los elementos configuradores de estos derechos, toda vez que en ese sentido se condicionarán las adecuadas eficacia y aplicabilidad inmediatas, así como su pronta justiciabilidad en el supuesto de violaciones o amenazas a su ejercicio o goce plenos. Por ello, la precisión de los contenidos esenciales mínimos, bien por la jurisprudencia constitucional o bien por una norma de rango legal, conducirá a identificar los ejes mínimos de protección y garantía que les brindarán los entes públicos. A partir de todo ello, el control judicial a que sea sometido el ejercicio de estos derechos por parte de sus titulares cobrará el protagonismo deseable por todos los que confiamos en la reafirmación de los derechos fundamentales como valores esenciales para la consecución de la dignidad plena de todos los seres humanos.

\section{BiBLIOGRAFÍA CITADA}

1) AleXY, Robert (1993), Teoría de los derechos fundamentales (Madrid, Centro de Estudios Constitucionales), p. 607.

2) Asensi Sabater, José (1996): Constitucionalismo y Derecho Constitucional. Materiales para una introducción (Valencia, España, Editorial Tirant LoBlanch), p. 238.

3) Cutié Mustelier, Danelia (1999), El sistema de garantías de los derechos humanos en Cuba, Tesis presentada en opción al Grado Científico de Doctora en Ciencias Jurídicas (Santiago de Cuba), p. 127.

4) Cutié Mustelier, Danelia, Ángel Mariño Castellanos y Josefina Méndez LÓPEZ (1998), "El sistema de garantías de los derechos fundamentales en Cuba”, en Colectivo de autores, Memorias de la IV Conferencia Cientifica sobre el Derecho (Mayagüez, Puerto Rico, Editorial), pp. 151-155.

5) _ (2000), "Reflexiones en torno a la protección de los derechos fundamentales en Cuba. Propuesta para su perfeccionamiento", en Lissette PÉREZ Hernández y Martha Prieto Valdés (Comp.) et al, Temas de Derecho Constitucional cubano (La Habana, Editorial Félix Varela), pp. 324-344.

6) Cutié Mustelier, Danelia y Josefina Méndez López (2006), "Tribunales y tutela de los Derechos Humanos en Cuba", en Colectivo DE AUTORES, Memorias de la Jornada Cientifica Internacional "Homenaje a la Constitución 
cubana de 1976 en su XXX Aniversario" (Santiago de Cuba, Ediciones UO), disponible en CD-ROM.

7) CAmps i Povill, Andreu (1993), "El artículo 43.3 de la Constitución española", en José Luis CarRetero Lestón (Coord.) et al, La Constitución y el deporte (Málaga, Junta de Andalucía), pp. 13-30.

8) D’Estéfano Pisani, Miguel Antonio (1988): Historia del Derecho Internacional. Desde 1917 hasta 1958 (La Habana, Editorial de Ciencias Sociales), p. 396.

9) Fernández Salgado, Michel (s.f.), "Breves consideraciones sobre los derechos humanos en la Constitución cubana", en Andry Matilla Correa (Coord.) et al., Introducción al estudio del Derecho (La Habana, Editorial Félix Varela), pp. 169-172.

10) Freixes Sanjuán, Teresa (1992): Constitución y derechos fundamentales (Barcelona, España, Editorial PPU), p. 451.

11) García Cotarelo, Ramón y Andrés de Blas Herrero (1986): Teoría del Estado y Sistemas Políticos, Tomo I (Madrid, Editorial UNED).

12) García de Enterría, Eduardo y Tomás-Ramón Fernández (2004): Curso de Derecho Administrativo, Volumen II, 9a edición (Madrid, Editorial ThomsonCivitas).

13) Gelli, María Angélica (2001): Constitución de la Nación argentina. Comentada y concordada (Buenos Aires, Editorial La Ley), pp. 995.

14) Hakansson Nieto, Carlos (2001): La Forma de Gobierno de la Constitución Peruana (Piura, Perú, Editorial de la Universidad de Piura), pp. 521.

15) Landa, César (2002), “Teorías de los derechos fundamentales”, en Cuestiones Constitucionales (No 6, enero-junio), pp. 49-71.

16) Mondelo García, José Walter (2006), "Regla de reconocimiento, Constitución y Valores Jurídicos", en Colectivo De AUTORes, Memorias de la Jornada Cientifica Internacional "Homenaje a la Constitución cubana de 1976 en su XXX Aniversario" (Santiago de Cuba, Ediciones UO), disponible en CD-ROM.

17) Pérez Hernández, Lissette y Martha Prieto Valdés (2000), "Los derechos fundamentales. Algunas consideraciones doctrinales necesarias para su análisis", en Lissette Pérez Hernández y Martha Prieto Valdés (Comp.) et al, Temas de Derecho Constitucional cubano (La Habana, Editorial Félix Varela), pp. 300-308.

18) Pérez LuÑo, Antonio Enrique (1994), Los derechos fundamentales, 2a edición (Madrid, Editorial Tecnos), p. 217. 
19) Pérez Royo, Javier (1997): Curso de Derecho Constitucional, $4^{a}$ edición (Madrid, Editorial, Marcial Pons), p. 805.

20) Prieto Valdés, Martha (2000): "Reflexiones sobre el carácter normativo de la Constitución”, en Lissette Pérez Hernández y Martha Prieto Valdés (Comp.) et al, Temas de Derecho Constitucional cubano (La Habana, Editorial Félix Varela), pp. 26-34.

21) _ (s.f.): "La Constitución", en Andry Matilla Correa (Coord.) et al, Introducción al estudio del Derecho (La Habana, Editorial Félix Varela), pp. 143-149.

22) __ (2002): El Derecho, la Constitución y su Interpretación, Tesis presentada en opción al Grado Científico de Doctora en Ciencias Jurídicas (La Habana, s.e.).

23) _ (2004), "Funciones de la Constitución”, en Revista Jurídica (Año 5, No 9), pp. 38-47.

24) Schmiтt, Carl (1927): Teoría de la Constitución (Madrid, Editorial Revista de Derecho Privado), p. 451.

25) Torrado, Fabio Raimundo (2003): Los derechos humanos en el sistema político cubano (La Habana, Editorial de Ciencias Sociales), p. 246.

26) Villabella Armengol, Carlos (2000 a), "Los derechos humanos. Consideraciones teóricas de su legitimación en la Constitución cubana”, en Lissette Pérez Hernández y Martha Prieto Valdés (Comp.) et al, Temas de Derecho Constitucional cubano (La Habana, Editorial Félix Varela), pp. 309-323. (2000 b), "La axiología de los derechos humanos en Cuba", en Lissette Pérez Hernández y Martha Prieto Valdés (Comp.) et al, Temas de Derecho Constitucional cubano (La Habana, Editorial Félix Varela), pp. 291-299. 
